\title{
Association between pulmonary function and peak oxygen uptake in elderly: the Generation 100 study
}

\author{
Erlend Hassel ${ }^{1,4^{*}}$ (D, Dorthe Stensvold ${ }^{1}$, Thomas Halvorsen ${ }^{2}$, Ulrik Wisløff ${ }^{1}$, Arnulf Langhammer ${ }^{3}$ \\ and Sigurd Steinshamn ${ }^{1,4}$
}

\begin{abstract}
Background: Although reduced function of the respiratory system limits peak oxygen uptake in diseases affecting the lungs or airways, the healthy respiratory system is thought to have a spare capacity for oxygen transport and uptake, and is not considered a limiting factor for peak oxygen uptake in healthy people. However, lung function declines with age and could theoretically limit peak oxygen uptake in elderly. We examined the association between peak oxygen uptake and lung function indices in an elderly population with the hypothesis that lung function indices would be associated with $\mathrm{VO}_{2 \text { peak }}$ up to a threshold value situated above the lower limits of normal lung function for our population.
\end{abstract}

Methods: Spirometry, gas diffusion tests and incremental work tests were performed in 1443 subjects (714 women) aged 69-77 years. Association between lung function indices and peak oxygen uptake was studied with hockey-stick regression.

Results: Forced expiratory volume in $1 \mathrm{~s}\left(\mathrm{FEV}_{1}\right)$ had a positive association with peak oxygen uptake up to, but not above, a threshold value of 2.86 | for men, and 2.13 I for women (lower limit of normal 2.73 and 1.77 | respectively).

A corresponding threshold was found for diffusing capacity of the lung for carbon monoxide ( $D_{\mathrm{Lco}}$ ) for men at $9.18 \mathrm{mmol} /$ $\mathrm{min} / \mathrm{kPa}$ (lower limit of normal $6.84 \mathrm{mmol} / \mathrm{min} / \mathrm{kPa}$ ). $D_{\llcorner\mathrm{LCO}}$ for women and $\mathrm{D}_{\mathrm{LCO}}$ divided by alveolar volume $\left(\mathrm{D}_{\mathrm{LCO}} \mathrm{NA}\right)$ for both sexes had a significant linear relationship to $\mathrm{VO}_{2 \text { peak }}(p<0.05)$, but no significant threshold value was found in these associations.

Conclusions: Threshold values for $\mathrm{FEV}_{1}$ for both sexes and $\mathrm{D}_{\mathrm{LcO}}$ for men were identified. These lung function indices had a positive association with $\mathrm{VO}_{2 \text { peak }}$ up to these threshold values, but not above. The identified threshold values were above lower limits of normal for $\mathrm{FEV}_{1}$ and $\mathrm{D}_{\mathrm{LCO}}$.

Keywords: Exercise and lung function, Respiratory physiology, Ageing

\section{Background}

It is generally accepted that maximal cardiac output is the principal limiting factor for peak oxygen uptake $\left(\mathrm{VO}_{2 \text { peak }}\right)$ in healthy individuals exercising at sea-level. By contrast the respiratory system has been considered to be structurally overbuilt both with respect to dynamic lung function and diffusion capacity, and is therefore

\footnotetext{
* Correspondence: erlend.hassel@ntnu.no

${ }^{1}$ K.G. Jebsen Center of Exercise in Medicine at Department of Circulation and Medical Imaging, Faculty of Medicine, Norwegian University of Science and Technology, Trondheim, Norway

${ }^{4}$ Clinic of Thoracic and Occupational Medicine, St. Olavs Hospital, Trondheim University Hospital, PO Box 3250, Sluppen, 7006 Trondheim, Norway Full list of author information is available at the end of the article
}

believed not to restrict oxygen uptake even during maximal exercise in non-endurance athletes $[1,2]$. Reduced lung function limits $\mathrm{VO}_{2 \text { peak }}$ in patients with pulmonary disease [3-7], but the association with $\mathrm{VO}_{2 \text { peak }}$ for lung function indices within the normal range is little studied.

In healthy ageing there is a steady decline of dynamic lung volumes. Expiratory flow is reduced and the flowvolume curve may resemble what is found in patients with chronic obstructive pulmonary disease [8]. The capacity of the lung for gas diffusion is also reduced with age [9]. Elderly have an increased dead space to tidal volume ventilation ratio compared to younger individuals 
and develop a marked alveolar to arterial oxygen gradient during exercise [10]. The spare capacity of the respiratory system is possibly reduced in elderly compared to middle-aged and young people, and both dynamic lung function and the diffusion capacity of the lungs may therefore be associated with reduced oxygen uptake even in healthy elderly people. This has previously not been examined in population based studies.

Given that the healthy respiratory system is overbuilt with respect to requirements for oxygen uptake, one would observe an association between lung function and $\mathrm{VO}_{2 \text { peak }}$ only when the capacity of the respiratory system is reduced below a threshold value which is below the lower limits of normal lung function. However, if the spare capacity of lung function is reduced with increasing age, this threshold may be found within the range of normal lung function in an elderly population, in that case suggesting that $\mathrm{VO}_{2 \text { peak }}$ may be limited by lung function in many healthy elderly. The present study examined the association between $\mathrm{VO}_{2 \text { peak }}$ and parameters from spirometry and gas diffusion tests in a large population based sample of elderly men and women.

We wanted to investigate if lung function indices were associated with $\mathrm{VO}_{2 \text { peak }}$ up to a threshold value above which further increase in lung function would not be associated with increasing VO2peak. If a threshold value were identified, we hypothesized that this threshold would be above the LLN (lower limits of normal) for lung function, i.e. within the normal range of lung function for this population.

\section{Methods}

\section{Study population}

The ongoing Generation 100 Study invited all inhabitants in the city of Trondheim, Norway, born between 01 January 1936 and 31 December $1942(n=6966)$ to a randomized controlled trial on the effect of exercise intervention on morbidity and mortality in an ageing population [11]. Study subjects were included from August 2012 to June 2013 giving a study population aged 69-77 years. The present study includes baseline data of participants that were able to perform exercise testing and training. Participants with chronic communicable infectious diseases, dementia, uncontrolled hypertension, heart failure, cardiomyopathy, severe arrhythmia, participating in other studies conflicting with Generation 100, or with conditions or test results indicating that testing or training could be unsafe were excluded. The Generation 100 Study and the present sub-study were approved by the Regional Committee for Medical Research Ethics (REK 2012/381 B) and all participants gave written informed consents.

\section{Examinations}

A symptom-limited incremental work test on a treadmill was performed to measure $\mathrm{VO}_{2 \text { peak }}$ using MetaMax II (Cortex, Leipzig, Germany) or Oxycon Pro (Erich Jaeger, Hoechberg, Germany) as previously described [12]. Participants not able to perform the test on a treadmill due to poor balance or other reasons performed the test on a cycle ergometer. Load was increased $1 \mathrm{~km} / \mathrm{h}$ or $2 \%$ inclination on the treadmill approximately every $90 \mathrm{~s}$ until exhaustion, on the bicycle load was increased $10 \mathrm{~W}$ every $30 \mathrm{~s}$. Testing of participants with suspected or previously diagnosed heart disease was supervised by a trained physician [13]. For simplicity the term $\mathrm{VO}_{2 \text { peak }}$ is used throughout this paper, even when referring to work by others that have reported maximum oxygen uptake. The participants reported average physical activity by answering three questions covering frequency, intensity and duration of physical activity. The answers were given different weights and a physical activity index was calculated as previously described [14].

Spirometry and gas diffusion test were performed with Sensormedics Vmax22 Encore (CareFusion, San Diego, USA) in accordance with the American Thoracic Society/European Respiratory Society recommendations $[15,16]$. The spirometer was calibrated daily. The study participants performed up to a maximum of eight spirometry trials until forced expiratory volume at $1 \mathrm{~s}\left(\mathrm{FEV}_{1}\right)$ and forced vital capacity (FVC) showed $<150 \mathrm{ml}$ variation between the two highest results. The highest values for vital capacity (forced expiratory or inspiratory) and $\mathrm{FEV}_{1}$ were recorded. No reversibility test was performed. For the day of testing, participants were instructed to continue any medication as usual, including anti-obstructive treatment. Predicted values and lower limit of normal (LLN) were calculated from Norwegian reference equations using age, sex and height [17].

Diffusing capacity of the lung for carbon monoxide $\left(D_{\mathrm{LCO}}\right)$ was measured by the single breath-method using a gas mixture containing $0.3 \%$ carbon monoxide and $0.3 \%$ methane. Estimated alveolar volume (VA) was calculated based on the dilution of methane from inspired to expired gas. The procedure was repeated with at least 4 min between each trial up to a maximum of 4 trials, until two tests of acceptable quality show $\mathrm{D}_{\mathrm{LCO}}$ within $1 \mathrm{mmol} / \mathrm{min} / \mathrm{kPa}$ or within $10 \%$ of the highest value and the mean of these values were recorded. Predicted values were calculated using equations developed for a comparable age group [18].

The spirometry and $\mathrm{D}_{\mathrm{LCO}}$-test were administered by a pulmonary care nurse or medical doctor and all measurements were quality controlled.

Body-fat percentage was measured with bioelectric impedance analysis (Inbody 720, Seoul, South Korea). In 
addition to the clinical tests, the participants filled out health-related questionnaires.

\section{Statistics}

All analyses were stratified by sex. A statistical procedure called hockey-stick regression was applied [19]. It assumes that the effect of variable $\mathrm{x}$ is best fitted by two continuous linear functions; the slopes of both lines and also the change-point where the two lines meet are estimated. The resulting combined fitted line has one slope up to a change-point on the $\mathrm{x}$-axis and a different slope after the change-point. Hockey-stick regressions with $\mathrm{VO}_{\text {2peak }}(\mathrm{ml} / \mathrm{min} / \mathrm{kg})$ as the dependent variable were performed; $\mathrm{FEV}_{1}, \mathrm{D}_{\mathrm{LCO}}$ and $\mathrm{D}_{\mathrm{LCO}}$ adjusted for alveolar volume $\left(D_{\mathrm{LCO}} / \mathrm{VA}\right)$ were tested as variables with changepoints in separate models. For comparison linear and curvilinear models were also fitted. In the linear models $\mathrm{FEV}_{1}, \mathrm{D}_{\mathrm{LCO}}$ and $\mathrm{D}_{\mathrm{LCO}} / \mathrm{VA}$ were added as linear variables; and in the curvilinear models these measurements were added as both linear and squared variables. The analyses were controlled for age, physical activity index, resting heart rate and body-fat percentage, smoking status and self-reported heart disease. Covariates were chosen based on previous prediction models for $\mathrm{VO}_{2 \text { peak }}$ $[14,20]$; self-reported heart disease was also added due to potential confounding in this age group. Control variables were continuous linear variables, except for current smoking (coded 1 or 0 ) and self-reported heart disease coded 1 for self-reported history of myocardial infarction, angina pectoris or atrial fibrillation, otherwise 0 . Chow test with null-hypothesis that intercept and coefficient are equal before and after change point were used to test for structural break at change-point, and ftest were used to compare hockey-stick and curvilinear models to linear models. All calculations were performed with Stata 13.1 (StataCorp, Texas, USA); hockeystick regressions were modelled with the "nl hockey" function.

\section{Results}

A total number of $1567 \mathrm{VO}_{2 \text { peak }}$-tests were completed; of these 47 on a cycle ergometer. Forty cases were omitted from the analyses due to submaximal effort (maximal selfreported value $<15$ on the $6-20$ Borg scale); and 84 were omitted due to missing physical activity score, smoking status, body-fat percentage or valid spirometry data. Descriptive statistics for the 1443 participants included in the analyses are shown in Table 1, histograms showing the distribution of $\mathrm{VO}_{2 \text { peak }}, \mathrm{FEV}_{1}$ and $\mathrm{D}_{\mathrm{LCO}}$ and $\mathrm{D}_{\mathrm{LCO}} / \mathrm{VA}$ are shown in Additional file 1.

Significant change-points in the association with $\mathrm{VO}_{2 \text { peak }}$ were found for $\mathrm{FEV}_{1}$ for men at $2.86 \mathrm{l}$ (LLN = $2.73 \mathrm{l})$ and for women at $2.13 \mathrm{l}(\mathrm{LLN}=1.77 \mathrm{l})$ (Table 2). The association between $\mathrm{FEV}_{1}$ and $\mathrm{VO}_{2 \text { peak }}$ was positive
Table 1 Descriptive statistics

\begin{tabular}{|c|c|c|}
\hline & $\begin{array}{l}\text { Males } \\
n=729\end{array}$ & $\begin{array}{l}\text { Females } \\
n=714\end{array}$ \\
\hline Age & $72.8 \pm 2.1$ & $72.9 \pm 2.1$ \\
\hline Height (cm) & $176.9 \pm 5.9$ & $163.4 \pm 5.3$ \\
\hline Weight (kg) & $82.5 \pm 11.3$ & $68.4 \pm 10.9$ \\
\hline Body mass index $\left(\mathrm{kg} / \mathrm{cm}^{2}\right)$ & $26.3 \pm 3.2$ & $25.6 \pm 3.8$ \\
\hline Body-fat percentage & $25.5 \pm 6.3$ & $34.7 \pm 7.0$ \\
\hline Resting heart rate (beats per minute) & $62.7 \pm 11.2$ & $66.8 \pm 10.0$ \\
\hline Physical activity index & $9.3 \pm 8.6$ & $8.0 \pm 8.7$ \\
\hline $\begin{array}{l}\text { Self-reported heart disease (\% yes) } \\
\text { (Ml, angina or atrial fibrillation) }\end{array}$ & $18.6 \%$ & $5.5 \%$ \\
\hline $\begin{array}{l}\text { Self-reported lung disease (\% yes) } \\
\text { (asthma, chronic bronchitis, } \\
\text { emphysema, chronic obstructive } \\
\text { pulmonary disease) }\end{array}$ & $10.8 \%$ & $12.5 \%$ \\
\hline \multicolumn{3}{|l|}{ Smoking status: } \\
\hline Never & $41.5 \%$ & $54.2 \%$ \\
\hline Former & $50.5 \%$ & $37.4 \%$ \\
\hline Current & $7.9 \%$ & $8.4 \%$ \\
\hline Pack years & $8.2 \pm 14.2$ & $4.9 \pm 10.5$ \\
\hline $\mathrm{FEV}_{1}$ (litres) & $3.13 \pm 0.60$ & $2.24 \pm 0.37$ \\
\hline $\mathrm{FEV}_{1} \%$ of predicted & $94.0 \pm 16.7$ & $102.4 \pm 15.9$ \\
\hline $\mathrm{FEV}_{1} / \mathrm{FVC}(\%)$ & $72.1 \pm 8.1$ & $73.4 \pm 6.6$ \\
\hline $\mathrm{D}_{\mathrm{LCO}}(\mathrm{mmol} / \mathrm{min} / \mathrm{kPa})$ & $9.04 \pm 1.68$ & $6.73 \pm 1.14$ \\
\hline$D_{\mathrm{LCO}} \%$ of predicted & $93.5 \pm 16.0$ & $86.3 \pm 13.5$ \\
\hline $\mathrm{D}_{\mathrm{LCO}} / \mathrm{VA}(\mathrm{mmol} / \mathrm{min} / \mathrm{kPa} / \mathrm{l})$ & $1.37 \pm 0.22$ & $1.40 \pm 0.20$ \\
\hline $\mathrm{D}_{\mathrm{LCO}} / \mathrm{NA} \%$ of predicted & $93.7 \pm 18.2$ & $84.8 \pm 11.9$ \\
\hline Peak oxygen uptake (ml/min/kg) & $31.3 \pm 6.7$ & $26.1 \pm 5.0$ \\
\hline Respiratory Exchange Ratio at peak work & $1.14 \pm 0.09$ & $1.10 \pm 0.09$ \\
\hline Peak heart rate (bpm) & $156.7 \pm 17.7$ & $156.5 \pm 15.9$ \\
\hline Ventilation at peak exercise (litres) & $96.4 \pm 21.2$ & $61.2 \pm 12.5$ \\
\hline
\end{tabular}

Definition of abbreviations: $\mathrm{Ml}=$ myocardial infarction; $\mathrm{FEV}_{1}=$ forced expiratory volume in $1 \mathrm{~s} ; \mathrm{FEV}_{1} / \mathrm{FVC}=\mathrm{FEV}_{1}$ divided by forced vital capacity; $\mathrm{D}_{\mathrm{LCO}}$ - diffusing capacity of the lung for carbon monoxide; $D_{L C O} / N A-D_{L C O}$ corrected for estimated alveolar volume. Values are given as percentage or mean \pm standard deviation

up to these values, but not above. The change-points correspond to the 31st and 28th percentile of measured $\mathrm{FEV}_{1}$, for men and women respectively. A change-point was also found in the association between $\mathrm{D}_{\mathrm{LCO}}$ and $\mathrm{VO}_{2 \text { peak }}$ for men at $9.18 \mathrm{mmol} / \mathrm{min} / \mathrm{kPa}$ $(\mathrm{LLN}=6.84 \mathrm{mmol} / \mathrm{min} / \mathrm{kPa})$, corresponding to the 54th percentile. No significant change-point in the association between $\mathrm{D}_{\mathrm{LCO}}$ and $\mathrm{VO}_{2 \text { peak }}$ was found for women. Furthermore, no significant change-points were found in the association between $\mathrm{D}_{\mathrm{LCO}} / \mathrm{VA}$ and $\mathrm{VO}_{2 \text { peak }}$ for either sex. Predicted effect plots for these hockey-stick regression models are shown in Fig. 1.

Explained variance (adjusted $\mathrm{R}^{2}$ ) for $\mathrm{VO}_{2 \text { peak }}$ from the hockey stick models were compared to corresponding 
Table 2 Change-point regression for association with peak oxygen uptake ( $\mathrm{ml} \mathrm{O} / 2 / \mathrm{min} / \mathrm{kg}$ )

\begin{tabular}{|c|c|c|c|}
\hline & Change point (95 \% Cl) & Left slope $(95 \%$ Cl) & Right slope (95 \% Cl) \\
\hline \multicolumn{4}{|l|}{ Men: } \\
\hline $\mathrm{FEV}_{1}(n=729)$ & 2.86 litres* $^{*}(2.54,3.17)$ & $4.58+(2.85,6.31)$ & $0.60(-0.56,1.75)$ \\
\hline $\mathrm{D}_{\mathrm{LCO}}(n=712)$ & $9.18 \mathrm{mmol} / \mathrm{min} / \mathrm{kPa}^{*}(8.32,10.05)$ & $1.57+(1.06,2.07)$ & $0.16(-0.37,0.68)$ \\
\hline$D_{\mathrm{LCO}} N A(n=712)$ & $1.36 \mathrm{mmol} / \mathrm{min} / \mathrm{kPa} / \mathrm{l}(0.99,1.74)$ & $8.54+(4.32,12.75)$ & $4.99+(0.89,9.08)$ \\
\hline \multicolumn{4}{|l|}{ Women: } \\
\hline $\mathrm{FEV}_{1}(n=714)$ & 2.13 litres * $(1.93,2.34)$ & $3.76+(1.60,5.92)$ & $-0.84(-2.22,0.55)$ \\
\hline $\mathrm{D}_{\mathrm{LCO}}(n=697)$ & $5.50 \mathrm{mmol} / \mathrm{min} / \mathrm{kPa}(4.45,6.56)$ & $1.54(-0.04,3.12)$ & $0.31(-0.01,0.62)$ \\
\hline $\mathrm{D}_{\mathrm{LCO}} N \mathrm{NA}(n=697)$ & $1.43 \mathrm{mmol} / \mathrm{min} / \mathrm{kPa} / \mathrm{l}(1.18,1.68)$ & $5.14 \dagger(2.37,7.91)$ & $1.25(-2.30,4.80)$ \\
\hline
\end{tabular}

Definition of abbreviations: $\mathrm{FEV}_{1}=$ forced expiratory volume in $1 \mathrm{~s} ; \mathrm{D}_{\mathrm{LCO}}$ - diffusing capacity of the lung for carbon monoxide; $\mathrm{D}_{\mathrm{LCO}} / \mathrm{VA}-\mathrm{D}_{\mathrm{LCO}}$ corrected for estimated alveolar volume. Non-linear "Hockey-stick" regressions for the associations between pulmonary function variables and peak oxygen uptake. * $p<0.01$ for hockey-stick model vs. linear model ( $\mathrm{f}$-test), $\uparrow p<0.01$ for slope being different from 0

linear and curvilinear models (Table 3). For the association between $\mathrm{FEV}_{1}$ and $\mathrm{VO}_{2 \text { peak }}$ the hockey-stick model gave higher $\mathrm{R}^{2}$-values than the linear and curvilinear models $\left(R^{2}=0.433\right.$ (hockey-stick) vs. 0.423 (linear) and 0.429 (curvilinear) for men, and $R^{2}=0.460$ (hockey-stick) vs. 0.452 (linear) and 0.456 (curvilinear) for women), supporting the choice of statistical model for this relationship. For $\mathrm{D}_{\mathrm{LCO}}$ the hockey-stick model was significantly better than the linear model for men $\left(R^{2}=0.450\right.$ vs. 0.440$)$, but not for women $\left(R^{2}=0.470\right.$ vs. 0.469$)$; and for both sexes $\mathrm{R}^{2}$-values from hockey-stick model were similar to $\mathrm{R}^{2}$ from curvilinear models (Table 3). For $\mathrm{D}_{\mathrm{LCO}}$ for women and for $\mathrm{D}_{\mathrm{LCO}} / \mathrm{VA}$ for either sex, neither the hockey stick model nor the curvilinear model was significantly better than the linear model, suggesting linear relationships. Full descriptions of models are presented in Additional file 2.

To evaluate the effects of self-reported physical activity on the identified change-points, sub-group analyses were performed separately on those reporting high physical activity (physical activity index $>=15$ ) and those reporting low activity (physical activity index $<15$ ). A physical activity index score of 15 corresponds to reporting exercise once a week with high intensity and duration $>30 \mathrm{~min}$; or exercise 2-3 times per week with moderate intensity and duration $>30 \mathrm{~min}$; or exercise almost every day of moderate intensity and duration $<30 \mathrm{~min}$. This cutpoint classifies $50.2 \%$ of men and $44.7 \%$ of women as reporting high physical activity. For men changepoints for $\mathrm{FEV}_{1}$ were $2.90 \mathrm{l}$ for those reporting high physical activity (LLN $=2.75 \mathrm{l}$ ) and $2.68 \mathrm{l}$ for those reporting low activity $(\mathrm{LLN}=2.73 \mathrm{l}$ ); the corresponding change-point localizations for $\mathrm{D}_{\mathrm{LCO}}$ were $11.0 \mathrm{mmol} / \mathrm{min} /$ $\mathrm{kPa}$ for high activity (LLN $=6.82 \mathrm{mmol} / \mathrm{min} / \mathrm{kPa}$ ) and $7.13 \mathrm{mmol} / \mathrm{min} / \mathrm{kPa}$ for low activity (LLN $=6.85 \mathrm{mmol} /$ $\mathrm{min} / \mathrm{kPa}$ ). For corresponding sub-groups of women the change-point values for $\mathrm{FEV}_{1}$ were $2.13 \mathrm{l}$ for high activity $(L L N=1.78 \mathrm{l})$ and $2.12 \mathrm{l}$ for low activity $(\mathrm{LLN}=1.77 \mathrm{l})$.

To assess the effect of lung disease in our analyses, selfreported pulmonary disease (history of asthma, chronic bronchitis, emphysema or chronic obstructive pulmonary disease) were tested as an independent variable in the regression analyses. Self-reported pulmonary disease was not a significant predictor for $\mathrm{VO}_{2 \text { peak }}$ in the hockey-stick model for $\mathrm{FEV}_{1}$ for either sex, and did not increase $\mathrm{R}^{2}$ or affect the identified threshold value. In the hockey-stick model for $\mathrm{D}_{\mathrm{LCO}}$ for men, self-reported pulmonary disease was a significant predictor for $\mathrm{VO}_{2 \text { peak }}$, but had only a minimal effect on the value, which decrease from 9.18 to $9.07 \mathrm{mmol} / \mathrm{min} / \mathrm{kPa}$.

\section{Discussion}

In this large population sample we have found evidence for a change-point in the association with $\mathrm{VO}_{2 \text { peak }}$ for $\mathrm{FEV}_{1}$ and $\mathrm{D}_{\mathrm{LCO}}$ in men and $\mathrm{FEV}_{1}$ in women. The associations between these variables and $\mathrm{VO}_{2 \text { peak }}$ were significant up to the change-points, but no significant associations were found above these values. This suggests that there may be a physiologic threshold for these lung function parameters, above which the lung function does not limit $\mathrm{VO}_{2 \text { peak. }}$. The identified threshold values are within the normal limits of lung function for this age group, which may suggest that lung function can be a limiting factor for maximal physical performance for many healthy elderly. A linear association with $\mathrm{VO}_{2 \text { peak }}$ was found for $\mathrm{D}_{\mathrm{LCO}}$ for women and $\mathrm{D}_{\mathrm{LCO}} / \mathrm{VA}$ for both sexes, but no significant threshold was found for these parameters.

The identified change-points for $\mathrm{FEV}_{1}$ equals $86 \%$ of predicted for men and $97 \%$ for women when age and height are set to sample means; and are higher than calculated LLN at $2.73 \mathrm{l}$ for men and $1.77 \mathrm{l}$ for women. Predicted values and LLN were calculated using relevant Norwegian reference equations [17]. If instead using the 2012 Global Lung Function Initiative equations [21] the change-points would be $93 \%$ of predicted $\mathrm{FEV}_{1}$ for men and $99 \%$ for women, so using the Norwegian reference values is the more conservative approach. The threshold for $\mathrm{D}_{\mathrm{LCO}}$ for men corresponds to $95 \%$ of predicted and is higher than LLN at $6.84 \mathrm{mmol} / \mathrm{min} / \mathrm{kPa}$. For the 


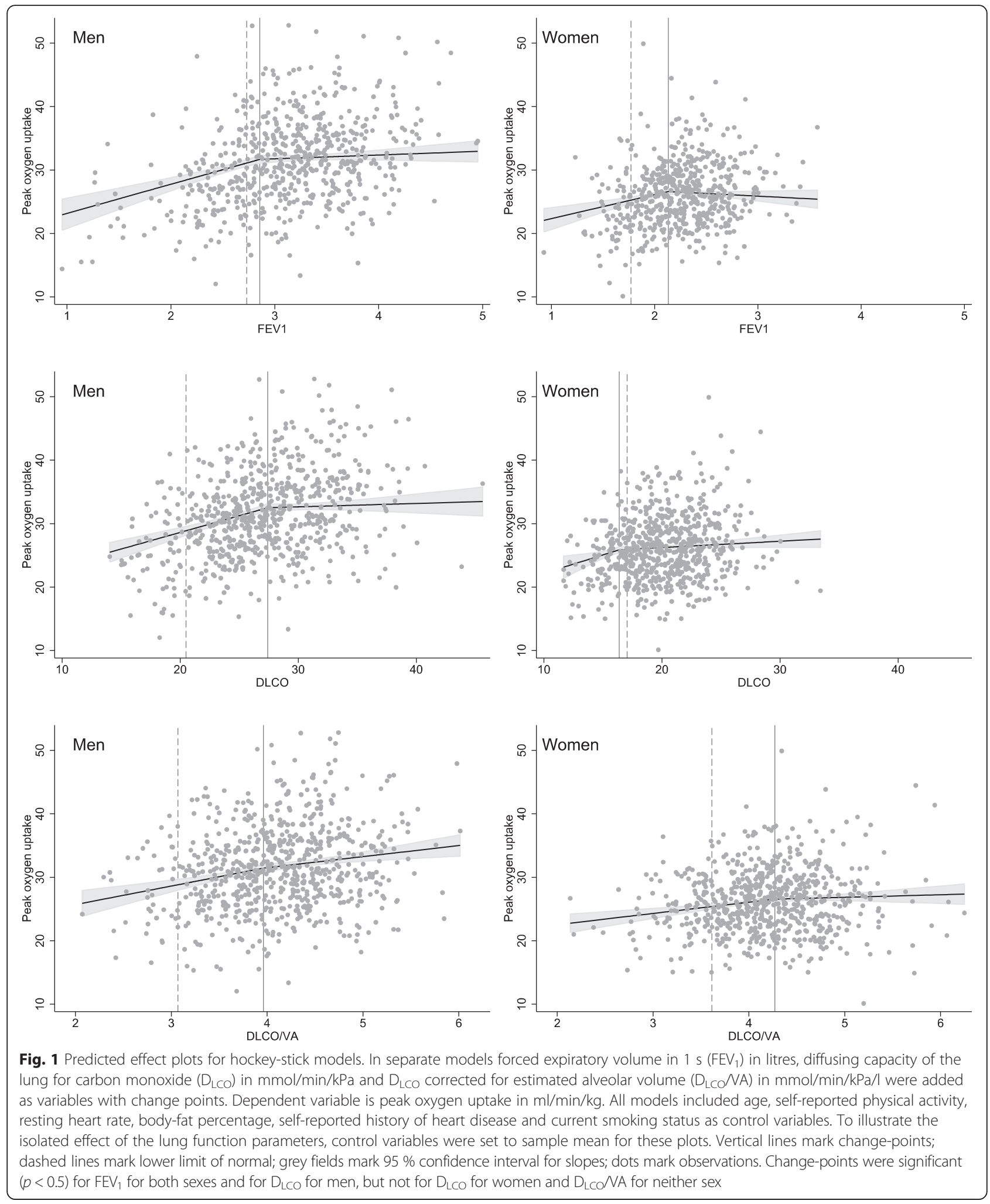

association between $\mathrm{D}_{\mathrm{LCO}}$ and $\mathrm{VO}_{2 \text { peak }}$ in women, neither the hockey-stick model nor the curvilinear model performed better than the multiple linear model; which may either be due to physiologic differences between sexes or to lack of statistical power to detect a levelling off of this relationship in women.

Several studies have shown that $\mathrm{VO}_{2 \text { peak }}$ is reduced in patients with lung disease and reduced lung function 
Table 3 Explained variance of $\mathrm{VO}_{2 \text { peak }}$ (Adjusted $\mathrm{R}^{2}$ ) of models with and without change points

\begin{tabular}{lccc}
\hline Added variable & Hockey-stick model & Linear model & Curvilinear model \\
\hline Men: & & & \\
FEV $_{1}$ & $0.433^{*}$ & 0.423 & $0.429^{*}$ \\
$D_{\mathrm{LCO}}$ & $0.450^{*}$ & 0.440 & $0.451^{*}$ \\
D $_{\mathrm{LCO}}$ NA & 0.440 & 0.441 & 0.441 \\
Women: & & & \\
FEV & $0.460^{*}$ & 0.452 & $0.456^{*}$ \\
$D_{\mathrm{LCO}}$ & 0.470 & 0.469 & 0.470 \\
$D_{\mathrm{LCO}} \mathrm{NA}$ & 0.477 & 0.476 & 0.477 \\
\hline
\end{tabular}

Definition of abbreviations: $\mathrm{VO}_{2 \text { peak }}=$ peak oxygen uptake; $\mathrm{FEV}_{1}=$ forced expiratory volume in $1 \mathrm{~s} ; \mathrm{D}_{\mathrm{LCO}}$ - diffusing capacity of the lung for carbon monoxide; $D_{L C O} / V A$ - $D_{L C O}$ corrected for estimated alveolar volume. Resulting explained variance (Adjusted $\mathrm{R}^{2}$ ) of regression models with peak oxygen uptake as dependent variable with variable in first column added either as a variable with change point, as a linear variable or as a curvilinear variable (both variable and variable ${ }^{2}$ ). Age, self-reported physical activity, resting heart rate, body-fat percentage, self-reported history of heart disease and current smoking status are control variables in all models. ${ }^{*}$-value $<0.05$ for $R^{2}$ change compared to linear model (f-test). Adjusted $\mathrm{R}^{2}$ for $\mathrm{VO}_{2 \text { peak }}$ in a multiple linear model without pulmonary function measurements, including only age, physical activity index, resting heart rate, body-fat percentage, smoking status and heart disease history were 0.393 for men and 0.448 for women

[3-6], but there are few studies on the relationship between pulmonary function measurements and $\mathrm{VO}_{2 \text { peak }}$ in healthy subjects. Babb et al. [22] reported a significant linear relationship between $\mathrm{FEV}_{1}$ and $\mathrm{VO}_{2 \text { peak }}$ in a small sample of asymptomatic volunteers selected to have a wide range of $\mathrm{FEV}_{1}(n=11$, age $=58 \pm 8$ years). Johnson et al. [23, 24] studying a group of active healthy older subjects $(n=30$, age $=70 \pm 1$ years) found a correlation between $\%$ of predicted $\mathrm{D}_{\mathrm{LCO}}$ and $\mathrm{VO}_{2 \text { peak }}$, and also showed that $\mathrm{FEV}_{1}$ were significantly higher in subjects with $\mathrm{VO}_{2 \text { peak }}$ above the median compared to those with $\mathrm{VO}_{2 \text { peak }}$ below the median. These studies had few participants and were not designed to study the association between lung function indices and $\mathrm{VO}_{2 \text { peak }}$, and they do not allow general conclusions about this association. On the other hand, in an interventional study, Sue-Chu et al. [25] examined the effect of the bronchodilator salbutamol on $\mathrm{VO}_{2 \text { peak }}$ in non-asthmatic highly-trained cross-country skiers with high $\mathrm{VO}_{2 \text { peak }}$. These subjects did not improve the $\mathrm{VO}_{2 \text { peak }}$ in spite of a significant improvement in $\mathrm{FEV}_{1}$, suggesting that even highly trained endurance athletes are not usually ventilatory limited with respect to $\mathrm{VO}_{2 \text { peak }}$. A significant proportion of highly fit endurance athletes develops arterial hypoxemia during sub-maximal or maximal exercise [26]. This exercise-induced arterial hypoxemia limits $\mathrm{VO}_{2 \text { peak }}$ and this limitation can be reversed by supplemental oxygen during exercise $[27,28]$, suggesting that diffusion capacity could be a limiting factor in these subjects.

Physical exercise improves the capacity of the cardiovascular and locomotor systems to transport and utilize oxygen, while no such effect is evident on the respiratory system. An improvement in the maximal function of the circulatory and muscular systems from exercise would therefore increase the demand on the respiratory system for oxygen transport, reducing any spare capacity of this system. We would therefore expect that the association between lung function indices and $\mathrm{VO}_{2 \text { peak }}$ would be significant up to higher levels of $\mathrm{FEV}_{1}$ and $\mathrm{D}_{\mathrm{LCO}}$ in an exercise-trained population compared to a more sedate one. This is in accordance with the sub-group analyses in our study showing change-points at higher levels of lung function in men with high self-reported physical activity compared to low self-reported activity. This effect is particularly pronounced for the association between $\mathrm{D}_{\mathrm{LCO}}$ and $\mathrm{VO}_{2 \text { peak}}$, suggesting that $\mathrm{D}_{\mathrm{LCO}}$ may represent a limiting factor for exercise capacity for men in this age group. For women, the location of the change point in the association between $\mathrm{FEV}_{1}$ and $\mathrm{VO}_{2 \text { peak }}$ is almost identical for those reporting high vs. low physical activity ( $2.13 \mathrm{vs.}$ $2.12 \mathrm{l})$.

The findings in our study may be due to the agerelated changes in the lung function of elderly people. With increasing age the lungs loose elastic recoil, the thorax wall gets stiffer and more restricted, respiratory muscle function is impaired, the alveolar surface area is reduced and there is increased ventilation-perfusion heterogeneity [29]. These changes cause expiratory flow limitation and reduced gas diffusion capacity in elderly compared to younger subjects. Even though there is a decline in the capacity for ventilation and gas exchange with age, there is also an age-related decline in the capacity of the other links of the oxygen uptake chain thus reducing the demands on the respiratory system. The margin between demand and capacity in the respiratory system decreases with age, but limitation of $\mathrm{VO}_{2 \text { peak }}$ due to demands exceeding the capacity is thought to be rare [30]. Our findings of an association with $\mathrm{VO}_{2 \text { peak }}$ for $\mathrm{FEV}_{1}$ and $\mathrm{D}_{\mathrm{LCO}}$ in the lower reference area may suggest that a reduced capacity of the respiratory system may be limiting for $\mathrm{VO}_{2 \text { peak }}$ for many elderly. The spare capacity of the lungs and airways seen in young healthy subjects may be fully eroded in many elderly, resulting in a limitation of $\mathrm{VO}_{2 \text { peak }}$ and maximal work rate by the respiratory system for these individuals.

The main strength of the present study is the population-based design and high number of subjects with directly measured $\mathrm{VO}_{2 \text { peak }}$ combined with spirometry and gas diffusion testing. To our knowledge, there are no other large studies examining the association between normal lung function and $\mathrm{VO}_{2 \text { peak }}$. Even though known or plausible confounders were controlled for in our analyses, there might still be some residual confounding. Unrecognized pulmonary disease may contribute to residual confounding, but since pulmonary 
function is already included in the analyses, pulmonary disease would have to affect $\mathrm{VO}_{2 \text { peak }}$ independently of pulmonary function if pulmonary disease were to be a confounder for this relationship. We cannot test whether unrecognized pulmonary disease affects the results, but we can test this for those with self-reported pulmonary disease. Self-reported pulmonary disease is a significant predictor of $\mathrm{VO}_{2 \text { peak }}$ only when $\mathrm{FEV}_{1}$ is not included in the analyses, indicating that pulmonary disease is an upstream variable of $\mathrm{FEV}_{1}$, and therefore not a relevant confounder in the analyses. Even though we have identified threshold levels in the associations between lung function indices and $\mathrm{VO}_{2 \text { peak }}$ on the population level for our subjects, the thresholds cannot be assumed to apply to individual subjects. Neither can we conclude that a subject having lung function below the threshold values has a pulmonary limitation of $\mathrm{VO}_{2 \text { peak. }}$. The physiologic basis for the observed change-point in the association between lung function indices and $\mathrm{VO}_{2 \text { peak }}$ may be age specific, and it cannot be assumed that the results in this study apply to younger or middle-aged populations. Ventilationperfusion heterogeneity and widened alveolar-arterial oxygen pressure gradient are likely to be important factors for the limiting effect of the respiratory system on $\mathrm{VO}_{2 \text { peak }}$; and measurements of blood oxygen concentration during exercise would likely have yielded further knowledge on this topic. Participants in this study were recruited to an exercise intervention study, and may be habitually physically active or at least more interested in exercise than the general population. This is a descriptive study with a cross-sectional design and it does not allow for conclusions on causality, and the results should therefore be interpreted with caution.

\section{Conclusions}

We have found evidence of a threshold in the association between lung function measurements and $\mathrm{VO}_{2 \text { peak }}$ in this elderly population. $\mathrm{FEV}_{1}$ for both sexes and for $\mathrm{D}_{\mathrm{LCO}}$ for men were positively associated with $\mathrm{VO}_{2 \text { peak }}$ only up to these threshold values. The identified threshold values are well within the normal range for these lung function parameters. $\mathrm{D}_{\mathrm{LCO}}$ for women and $\mathrm{D}_{\mathrm{LCO}} /$ VA for both sexes were linearly associated with $\mathrm{VO}_{2 \text { peak }}$. A possible explanation for our findings could be that lung function even within the normal range may be a limiting factor for maximal oxygen uptake for many elderly.

\section{Additional files}

Additional file 1: Histograms showing the distribution of measured $\mathrm{VO}_{2 \text { peak, }} \mathrm{FEV}_{1}, \mathrm{D}_{\text {LCo }}$ and $\mathrm{D}_{\text {LCO }} / \mathrm{VA}$ by sex. (JPG $547 \mathrm{~kb}$ )

Additional file 2: Word document. Full description of models. Description of statistical models with coefficients. (DOCX $22 \mathrm{~kb}$ )

\section{Competing interests}

The authors declare that they have no competing interests.

\section{Authors' contributions}

$E H, D S, T H, U W, A L$ and SS contributed substantially to the study design, acquisition or analysis of data, and the writing of the manuscript. All authors critically reviewed the manuscript and approved of the final version.

\section{Acknowledgements}

The study was funded by The Kristian Gerhard Jebsen Foundation and Norwegian Health Association.

\section{Author details}

${ }^{1}$ K.G. Jebsen Center of Exercise in Medicine at Department of Circulation and Medical Imaging, Faculty of Medicine, Norwegian University of Science and Technology, Trondheim, Norway. ${ }^{2}$ SINTEF Technology and Society, Department of Health Research, PO Box 4760, Sluppen, N 7465 Trondheim, Norway. ${ }^{3}$ Department of Public Health and General Practice, Faculty of Medicine, Norwegian University of Science and Technology, Trondheim, Norway. ${ }^{4}$ Clinic of Thoracic and Occupational Medicine, St. Olavs Hospital, Trondheim University Hospital, PO Box 3250, Sluppen, 7006 Trondheim, Norway.

Received: 26 September 2015 Accepted: 22 December 2015

Published online: 30 December 2015

\section{References}

1. Dempsey JA, McKenzie DC, Haverkamp HC, Eldridge MW. Update in the understanding of respiratory limitations to exercise performance in fit, active adults. Chest. 2008:134:613-22.

2. Romer LM, Sheel AW, Harms CA. The Respiratory System. In: Farrell PA, Joyner MJ, Caiozzo VJ, editors. ACSM's Advanced Exercise Physiology. 2nd ed. Philadelphia, PA: Lippincott Williams \& Wilkins; 2012. p. 242-96.

3. Carlson DJ, Ries AL, Kaplan RM. Prediction of maximum exercise tolerance in patients with COPD. Chest. 1991;100:307-11.

4. Babb TG, Viggiano R, Hurley B, Staats B, Rodarte JR. Effect of mild-to-moderate airflow limitation on exercise capacity. J Appl Physiol. 1991;70:223-30.

5. Cahalin L, Pappagianopoulos P, Prevost S, Wain J, Ginns L. The relationship of the 6-min walk test to maximal oxygen consumption in transplant candidates with end-stage lung disease. Chest. 1995;108:452-9.

6. Carter R, Holiday DB, Stocks J, Grothues C, Tiep B. Predicting oxygen uptake for men and women with moderate to severe chronic obstructive pulmonary disease. Arch Phys Med Rehabil. 2003;84:1158-64.

7. Chin RC, Guenette JA, Cheng S, Raghavan N, Amornputtisathaporn N, Cortes-Telles A, et al. Does the respiratory system limit exercise in mild chronic obstructive pulmonary disease? Am J Respir Crit Care Med. 2013;187:1315-23.

8. Hardie JA, Buist AS, Vollmer WM, Ellingsen I, Bakke PS, Morkve O. Risk of over-diagnosis of COPD in asymptomatic elderly never-smokers. Eur Respir J. 2002;20:1117-22.

9. Guenard H, Marthan R. Pulmonary gas exchange in elderly subjects. Eur Respir J. 1996:9:2573-7.

10. Venturelli M, Schena F, Scarsini R, Muti E, Richardson RS. Limitations to exercise in female centenarians: evidence that muscular efficiency tempers the impact of failing lungs. Age (Dordr). 2013;35:861-70.

11. Stensvold D, Viken H, Rognmo O, Skogvoll E, Steinshamn S, Vatten $\sqcup$, et al. A randomised controlled study of the long-term effects of exercise training on mortality in elderly people: study protocol for the Generation 100 study. BMJ Open. 2015:5:e007519.

12. Wisloff U, Stoylen A, Loennechen JP, Bruvold M, Rognmo O, Haram PM, et al. Superior cardiovascular effect of aerobic interval training versus moderate continuous training in heart failure patients: a randomized study. Circulation. 2007:115:3086-94.

13. Gibbons RJ, Balady GJ, Beasley JW, Bricker JT, Duvernoy WF, Froelicher VF, et al. ACC/AHA Guidelines for Exercise Testing. A report of the American College of Cardiology/American Heart Association Task Force on Practice Guidelines (Committee on Exercise Testing). J Am Coll Cardiol. 1997:30:260-311.

14. Nes BM, Janszky I, Vatten LJ, Nilsen TI, Aspenes ST, Wisloff U. Estimating V.O 2 peak from a nonexercise prediction model: the HUNT Study, Norway. Med Sci Sports Exerc. 2011:43:2024-30. 
15. Miller MR, Hankinson J, Brusasco V, Burgos F, Casaburi R, Coates A, et al. Standardisation of spirometry. Eur Respir J. 2005;26:319-38.

16. Macintyre N, Crapo RO, Viegi G, Johnson DC, van der Grinten CP, Brusasco V, et al. Standardisation of the single-breath determination of carbon monoxide uptake in the lung. Eur Respir J. 2005;26:720-35.

17. Langhammer A, Johnsen R, Gulsvik A, Holmen TL, Bjermer L. Forced spirometry reference values for Norwegian adults: the Bronchial Obstruction in Nord-Trondelag Study. Eur Respir J. 2001;18:770-9.

18. Garcia-Rio F, Dorgham A, Galera R, Casitas R, Martinez E, Alvarez-Sala R, et al, Prediction equations for single-breath diffusing capacity in subjects aged 65 to 85 years. Chest. 2012;142:175-84.

19. Bacon DW, Watts DG. Estimating the Transition between Two Intersecting Straight Lines. Biometrika. 1971;58:525-34.

20. Jackson AS, Sui X, O'Connor DP, Church TS, Lee DC, Artero EG, et al. Longitudinal cardiorespiratory fitness algorithms for clinical settings. Am J Prev Med. 2012;43:512-9.

21. Quanjer PH, Stanojevic S, Cole TJ, Baur X, Hall GL, Culver BH, et al. Multi-ethnic reference values for spirometry for the 3-95-yr age range: the global lung function 2012 equations. Eur Respir J. 2012;40:1324-43.

22. Babb TG, Long KA, Rodarte JR. The relationship between maximal expiratory flow and increases of maximal exercise capacity with exercise training. Am J Respir Crit Care Med. 1997:156:116-21.

23. Johnson BD, Reddan WG, Pegelow DF, Seow KC, Dempsey JA. Flow limitation and regulation of functional residual capacity during exercise in a physically active aging population. Am Rev Respir Dis. 1991;143:960-7.

24. Johnson BD, Badr MS, Dempsey JA. Impact of the aging pulmonary system on the response to exercise. Clin Chest Med. 1994;15:229-46.

25. Sue-Chu M, Sandsund M, Helgerud J, Reinertsen RE, Bjermer L. Salmeterol and physical performance at -15 degrees $C$ in highly trained nonasthmatic cross-country skiers. Scand J Med Sci Sports. 1999;9:48-52.

26. Dempsey JA, Wagner PD. Exercise-induced arterial hypoxemia. J Appl Physiol (1985). 1999;87:1997-2006.

27. Powers SK, Lawler J, Dempsey JA, Dodd S, Landry G. Effects of incomplete pulmonary gas exchange on VO2 max. J Appl Physiol (1985). 1989;66:2491-5.

28. Harms CA, McClaran SR, Nickele GA, Pegelow DF, Nelson WB, Dempsey JA. Effect of exercise-induced arterial $\mathrm{O} 2$ desaturation on $\mathrm{VO} 2 \mathrm{max}$ in women. Med Sci Sports Exerc. 2000:32:1101-8.

29. Janssens JP, Pache JC, Nicod LP. Physiological changes in respiratory function associated with ageing. Eur Respir J. 1999:13:197-205.

30. Johnson BD, Dempsey JA. Demand vs. capacity in the aging pulmonary system. Exerc Sport Sci Rev. 1991;19:171-210.

\section{Submit your next manuscript to BioMed Central and we will help you at every step:}

- We accept pre-submission inquiries

- Our selector tool helps you to find the most relevant journal

- We provide round the clock customer support

- Convenient online submission

- Thorough peer review

- Inclusion in PubMed and all major indexing services

- Maximum visibility for your research

Submit your manuscript at www.biomedcentral.com/submit

) Biomed Central 